\title{
Derechos humanitarios como prospectiva de los derechos humanos en Latinoamérica
}

\section{Humanitarian rights as a prospective of human rights in Latin America}

\author{
DOI: $\quad$ https://doi.org/10.17981/juridcuc.16.1.2020.03
}

Fecha de Recepción: 11/07/2019. Fecha de Aceptación: 19/09/2019

\author{
Jaime Bermejo Galán \\ Universidad Simón Bolívar. Barranquilla (Colombia) \\ jaimecamilob@hotmail.com
}

Juan José Lamadrid

Universidad Libre, Barranquilla (Colombia) juanjlamadrid@hotmail.com

Para citar este artículo:

Bermejo, J. y Lamadrid, J. (2020). Derechos humanitarios como prospectiva de los derechos humanos en Latinoamérica. JURÍDICAS CUC, 16(1). 69-96. DOI: http://dx.doi.org/10.17981/ juridcuc.16.1.2020.03

Resumen

En un breviario teórico, a partir de la metodología del análisis de contenido y la hermenéutica, se realiza un examen de los derechos humanitarios como prospectiva de los derechos humanos en Latinoamérica, ante la desmedida crisis actual, evidenciada en atropellos, desmanes, injusticias e inequidades, las cuales han desencadenado, como corolario, la pérdida de la dignidad del hombre, ente supremo del mundo. Ante tal devastación moral, y una vez examinadas las referencias teóricas expuestas, es de rigor concluir como las sociedades deben retomar los fundamentos que han servido de base teleológica a las legislaciones en Latinoamérica, buscando, como solución, el verdadero propósito humanizante que perfile de manera eficiente el espíritu legislativo y la praxis cotidiana.

Palabras clave: Derechos humanitarios-prospectiva; derechos humanos-Latinoamérica; Dignidad Humana

\section{Abstract}

In a theoretical brief, based on the methodology of content analysis and hermeneutics, an examination is made of humanitarian rights as a prospective for human rights in Latin America, in the face of the current excessive crisis, evidenced by abuses, excesses, injustices and inequities, which have triggered, as a corollary, the loss of human dignity, the supreme entity of the world. In the face of such moral devastation, and once the theoretical references set forth have been examined, it is essential to conclude how societies should retake the foundations that have served as the teleological basis for legislation in Latin America, seeking, as a solution, the true humanizing purpose that efficiently shapes the legislative spirit and daily practice.

Keywords: Humanitarian rights-foresight; human rights-Latin America; Human dignity. 


\section{INTRODUCCIÓN}

Resulta ineludible en un trabajo investigativo de esta índole obviar la definición de expertos del Departamento de Derecho Internacional (DDI) de la Organización de Estados Americanos (OEA) acerca del Derecho Internacional Humanitario (DIH), para quienes este se constituye en la rama del derecho internacional destinado a limitar y evitar el sufrimiento humano en tiempo de conflicto armado (DDI, 2019).

De la misma manera, en términos de versados de la Cruz Roja Española (2018) se alude al Derecho Internacional Humanitario (DIH) como un conjunto de normas internacionales de origen convencional y consuetudinario, específicamente destinado a ser aplicado en los conflictos armados, internacionales o no. Este conjunto de normas restringe, por consideraciones humanitarias, el derecho de las partes en conflicto a elegir voluntariamente los métodos (modos) y medios (armas) de hacer la guerra, y protege a las personas en su integridad y los bienes afectados o que puedan resultar afectados por ella.

Destaca, primeramente, como el DIH se encontraba conformado por dos vertientes diferentes, las cuales son en primer lugar el Derecho de la Haya, el cual regula aquellas disposiciones frente a los medios y métodos de combate, y en segundo lugar el Derecho de Ginebra el cual consiste en aquellas normas que van direccionadas para la protección de las víctimas en los conflictos armados, igualmente se resalta la Resolución 2444 (Organización de las Naciones Unidas-ONU, 1968) en lo atinente al respeto de los DDHH en los conflictos armados, y fundamentalmente aquellos que están inmerso en los Protocolos Adicionales a los Convenios de Ginebra en 1977 (CICR, 2007).

Como se puede observar de las anteriores disposiciones existe una relación muy fraterniza debido a que pone de manifiesto la protección integral y con mayor vehemencia de las personas y bienes víctimas del conflicto armado (heridos, enfermos, náufragos, prisioneros de guerra, población civil, y por extensión, los bienes culturales, los bienes indispensables para la supervivencia de la población civil y 
el medio ambiente natural), estableciendo una limitante para el uso de la fuerza y sobre todo estableciendo un conjunto de reglas sobre como dirigir el uso de los elementos de guerra y el manejo de las hostilidades entre partes en conflicto (CICR, 2007).

Ahora bien, sobre el Derecho Internacional Humanitario (DIH), se han producido avances pertinentes y considerables, al menos en el papel, si se parte de la intervención producida por los legisladores en diferentes normativas internacionales y en los diferentes encuentros y foros producidos en todos los ámbitos de discusión, declaraciones, publicaciones, aportes de nuevas doctrinas por diferentes autores de talla internacional, así como de aquellos organismos internacionales de vigilancia investigación y de recepción de denuncias, los cuales han jugado un papel fundamental en materia de protección de los DDHH y de la implementación del DDHH. Perspectiva desde la cual hoy debe entenderse que su internacionalización es incontenible.

Es así como, para su eficacia y garantía, según Uribe (1983), funcionan las Cortes Internacionales de los Derechos Humanos, en el continente americano y en el europeo, con sedes en San José de Costa Rica y Estamburgo, paralelos a la Comisión Africana de los Derechos Humanos y de los Pueblos, ante las cuales podrán acudir las personas naturales cuando no obtengan la protección y reconocimiento de sus derechos en el ordenamiento y la jurisdicción nacionales.

Hoy en día gracias al reconocimiento de los DDHH a través de declaraciones universales o instrumentos internacionales que reconocen derechos humanos, los países cuando expiden sus constituciones, reconocen en su parte dogmática esos derechos además de aquellas garantías que establecen el disfrute y gozo de esos DDHH, asimismo de los mecanismos constitucionales para la protección y defensa de los mismos, e igualmente se resalta aquellas constituciones que no son modernas o han actualizado sus constituciones, estableciendo nuevos derechos en sus ordenamientos internos, colocándose a tono con las nuevas disposiciones.

Así, frente a estos lineamientos, irrumpe con fuerza en la actualidad la tercera generación de derechos humanos. Sobre esta base, se alude a los derechos de la solidaridad, constituyendo los mismos, en 
el criterio de Bustamante (2010), una tercera generación propia de la segunda mitad del siglo XX. Devenidos de la primera y segunda generación, vale decir, derechos civiles y políticos del hombre, y los derechos económicos y sociales, los cuales apuntan, indefectiblemente, a los denominados derechos de cuarta generación con la finalidad de contribuir al desarrollo efectivo de la ciudadanía, sobre todo en el contexto de las redes sociales y la lucha contra la exclusión digital, desde donde se diversifican aún más las relaciones personales, laborales y sociales de los individuos.

Debe destacarse el énfasis actual en el cual se ubican los DDHH de tercera generación, los cuales aparecen en la cotidianidad como manifestaciones de grupos sociales minoritarios o marginados, sea por factores como la edad, etnias o religión, en aquellos países del mal llamado Tercer Mundo, comunidades o grupos sociales que se ven afectados por múltiples flagelos, devenidos de las múltiples manifestaciones que percibe la discriminación económico-social. Incluso, en los últimos años, como derechos que han ido alcanzando un rol cada vez más ponderante, lo cual ha generado un gran desarrollo al respeto y la conservación de la diversidad cultural, la protección del medio ambiente y la conservación del patrimonio cultural de la humanidad, entre otros.

En este sentido, la solidaridad cobra vigencia en el espíritu de la mayoría, sobre todo en estos tiempos de crisis humanitaria que viven los países, desde la visión política, social, económica y cultural. Pero, sobre la cual, intervenidos los espacios de opresión y miseria humana, pudiera fundarse el reinado de la paz, siempre y cuando se asuma la conciencia democrática de los pueblos, y el establecimiento del estado de bienestar y del buen vivir de sus ciudadanos.

Con base en lo expuesto, urge hacer un llamado a practicar la natural vocación humana acerca de la plenitud de la existencia, acerca del don sagrado de la vida y su carácter teleológico. Con este ideal, asumir el propósito de la solidaridad como necesaria para fundamentar, en las legislaciones y en la conciencia, los controles jurídicos y las precauciones bélicas, pudiendo en tal sentido decir adiós a la desigualdad, a la violencia, a las armas y a la guerra. 
Internacionalización de los derechos humanitarios... garantía de cumplimiento

Ha de aludirse, de primer orden, a la universalidad de los derechos humanos, al igual que la importancia de los procesos proceso histórico-político en el reconocimiento de los mismos. Serrano y Vázquez (2016) manifiestan que la igualdad, junto al nacimiento de los DDHH como derechos naturales, rompieron con aquella concepción o creencia de una comunidad políticamente dominante y estructuralmente organizada, la cual era sometida a una de oscuridad y comienza a construirse en una sociedad política individualista donde el todo ya no será más importante que la parte. El proceso político que se encuentra detrás es el paso del súbdito al ciudadano.

Cabe destacar aquellos derechos que van jalonando el poder político, como una limitante al mismo, es decir, los derechos y el poder político ya no vendrán como "naturalidad esencial de la persona", sino que su fundamento provendrá de un proceso de deliberación que permite razonablemente pensar en esos derechos del hombre como fundamentales (independientemente de que el fundamento sea la dignidad humana, la agencia o el sentimentalismo). Serrano y Vázquez (2016), en ese mismo orden de ideas señalan que los DDHH y el DIH, tienen algo similar, y es que los dos ordenamientos jurídicos hacen parte de un conjunto de normas de carácter internacional cuya finalidad es la protección y defensa de los DDHH.

En un criterio que se mantiene vigente en el tiempo, los DDHH y el DIH tienen como características principales el ser instrumentos de carácter supranacional, los cuales están concebidos bajo principios generales del derecho; principios que todo ordenamiento jurídico, ya sea nacional o internacional tienen, y que una vez reconocidos son de obligatorio cumplimiento para el Estado. Además, como otra característica, a pesar de sus características o semejanzas, en cada uno de estos sub-sistemas las reglas y la normatividad son instituidas por mecanismos semejantes y aquellas fuentes establecidas en convenciones como aquellas de rango consuetudinario. Así mismo, 
se expresa que la vulneración de algunas de sus disposiciones activa los mecanismos de defensa y protocolos del derecho internacional de los derechos humanos, referente a la responsabilidad internacional de los Estados, así como de las personas que violente los DDHH. Bajo esa perspectiva, estando regulados hoy, tanto los DDHH como el DIH por el derecho internacional, ambos sub-sistemas tienden en esencia a limitar o restringir las facultades propias del Estado que hacen a su soberanía.

Esos límites a la soberanía estatal se justifican en razón a la necesidad de proteger a los individuos frente a actos arbitrarios del Estado al cual hacen parte y evitar que vulneren sus derechos garantizados en los instrumentos internacionales. Es así como la finalidad de los DDHH radica en satisfacer el pleno goce de las libertades y garantías individuales de las personas, su bienestar, así como los mecanismos para su protección, a diferencia del DIH, el cual su finalidad consiste en la protección de los derechos de las víctimas de un conflicto armado, ya sea de orden interno o externo, como se puede observar a pesar que se aplican en contexto diferentes. Estas herramientas se complementan y/o son concomitantes en la protección de los derechos humanos de los individuos, es decir hay un interés entre estas normas en la protección de las personas en todo tiempo o circunstancia.

Se reitera que los DDHH y el DIH surgieron en diferentes contextos. Los DDHH, los primeros surgieron como producto de los conflictos internos de los Estados y se encuentran hoy en día en las constituciones políticas de los Estados en su parte dogmática. Igualmente hay unos instrumentos de carácter internacional que garantizan los DDHH y que se pueden aplicar de forma automática, como en el caso colombiano (Constitución política, art. 93, 1991) donde se establece por parte del constituyente una expresa autorización en la aplicación de instrumentos que reconozcan derechos humanos y se apliquen de forma automática como si fuera una norma del derecho interno, resaltando igualmente el ejercicio pleno la soberanía de cada Estado para permitir su vinculatoria en un ordenamiento jurídico supranacional, 
Los segundos surgen como una manifestación de los Estados durante la segunda parte del siglo XIX, ante los hechos que se tradujeron en las diferentes violaciones a la dignidad humana y todas aquellas barbaridades que germinaron de la guerra. Es así como el DIH surge como una corriente internacional por parte de los Estados con fines no políticos, sino como una fuente para entrar a regular el derecho de las personas dentro un conflicto armado y crear unos límites al uso de la fuerza.

Con la internacionalización de los DDHH se establecieron nuevos planteamientos acerca de la protección de los mismos en la legislación interna de los Estados. Es decir, hoy en día el principio de no intervención en aquellos asuntos de competencia exclusiva de la jurisdicción de un país, lo cual es una característica del concepto de soberanía, se encuentra revaluado ante la vulneración de DDHH de un Estado que forme parte o no de un tratado que garantice los derechos humanos y con la creación de organismos internacionales que velan por los DDHH, los cuales juegan un papel activo en la defensa de estos, buscando garantizar a nivel internacional la existencia de una estabilidad frente a la paz.

Igualmente se puede resaltar que esa limitante al Estado en su poder de autoridad, se da por la inclusión de las diferentes categorías de víctimas de los conflictos en armas, ya sea de forma externa o interna, situación que generó que los Estados, los organismos internacionales y la firma de convenios sobre DDHH y DIH reconocieran los derechos de los heridos, enfermos de la guerra, náufragos y prisioneros de guerra, entre otros, lo cual finalmente se concluyó en la reglamentación de la población civil afectada por conflictos armados y especialmente a los niños y las mujeres (Sánchez, 2007 y Narváez, Matzumoto, Mira-Olano y Zúñiga-Bolívar, 2019).

En tal sentido, el derecho humanitario ha ido perfilando sus fundamentos. El corpus iuris del Derecho Internacional de los Derechos Humanos se conforma a partir de instrumentos internacionales de contenidos, además de efectos jurídicos diversos, como lo señala O'Donnell (2004). tales como tratados, convenios, resoluciones y declaraciones. Tales instrumentos junto a aquellas normativas propias 
del Derecho Internacional Humanitario han reconocido que las víctimas de graves violaciones a los Derechos Humanos, tienen por lo menos cuatro tipos de derechos, que son: el derecho a la verdad, el derecho a la justicia, el derecho a la reparación y a las garantías de no repetición.

Es así entonces que, en principio, esos derechos surgen, de la conformación de dos cuerpos de normas conocidos como el Derecho de Ginebra y el Derecho de La Haya, lo que se ha dado en llamar jus in bello (el derecho aplicable en la guerra), los cuales, con el transcurrir de los tiempos, y en razón de su necesidad de implantación, han generado otras disposiciones aplicables en cada país en particular donde la crisis humanitaria ha mermado la calidad de vida de los ciudadanos. En este mismo sentido, cada nación, acogiendo las disposiciones iniciales mencionadas, adecua las normas a sus exigencias y necesidades particulares.

Cabe destacar el aporte de Perren-Klinger (2015), quien refiere la relevancia de la Comisión Internacional Humanitaria de Encuesta (CIHE), pero a la vez, la imposibilidad de la Comisión de llevar a cabo su mandato de monitorear casos de violaciones de DIH, lo cual ha traído graves implicaciones para el respeto de las normas. Esta comisión es un organismo creado en 1991 para investigar las quejas sobre presuntas infracciones o violaciones graves al DIH. Señala la mencionada actora internacional que el monitoreo es algo difícil y, desde su visión, muchos estados temen todavía, que sería lo mismo que denunciar, lo que no hace la Comisión. Además, muchas veces, firmar y hasta ratificar las normas humanitarias es fácil, y después cumplir es más difícil. Hay temores de que la Comisión quiera ampliar su competencia hacia temas de derechos humanos, cuando el núcleo duro que se respeta también en conflictos armados es el DIH.

Por su parte, Camen (2015), asesor legal de la Comisión de Derecho Internacional Humanitario del Comité Internacional de la Cruz Roja (CICR) para América Latina y el Caribe, advierte que la implementación de los tratados humanitarios no es una opción. Son obligaciones asumidas por los Estados y no solo aplican cuando un país tiene un conflicto armado, sino también cuando no hay conflicto 
armado y una forma de prevenir que ocurran los conflictos es tomar medidas nacionales. Es una ocasión rara, porque no hay todos los años un tipo de intercambio, donde los Estados pueden discutir con su contraparte sobre cuestiones de derechos humanitarios, pero es una iniciativa que debe ser lograda.

El tratado más reciente relacionado con el derecho humanitario, discutido en la Conferencia, fue el Tratado sobre Comercio de Armas (ONU, 2018). En muchos países de la región hay un problema de seguridad y de violencia que genera muchas necesidades humanitarias, y en muchos casos los medios que se utilizan para ese tipo de violencia son las armas de fuego. El efecto directo es estar en un tiroteo, pero también se reduce el acceso a servicios de salud, de educación o el libre movimiento. Entonces, la aplicación de ese tratado puede tener una incidencia para mucha gente en nuestra región.

Destaca Gasser (2010), en una suerte de conclusión anticipada de este estudio, como el DIH se encuentra destinado, resaltando los instrumentos de mayor relevancia en el Derecho Internacional de los Derechos Humanos, con los Convenios de Ginebra de 1949 para la protección de las víctimas de la guerra, así como con los Protocolos adicionales de 1977 (CICR, 2007), instrumentos que reiteran la génesis del DIH actual, los cuales fueron fruto de un gran trabajo mancomunado de negociaciones de carácter político, aportes financieros por parte de los organismos y Estados interesados en establecer unos mecanismos en la protección de los DDHH y tener fija unas reglas de combate en algún momento que su soberanía fuera perturbada; reglas que se consideraron necesarias en razón al desbordamiento al maltrato de los derechos humanos de las personas en tiempo de guerra.

Un nuevo humanismo...

eficacia de los Derechos Humanitarios

ante una sociedad en crisis axiológica

Uno de los valores fundamentales del hombre es la solidaridad. Sobre el particular, ha de hacerse énfasis en que este valor o principio social fundamental se presenta como una fórmula expedita si se 
pretende el acompañamiento, la ayuda humanitaria ante situaciones de crisis, devenidas de conflictos bélicos, desbordada en razón de la ausencia de valores humanos, que hace inducir la mentada crisis axiológica en los individuos.

$\mathrm{Al}$ respecto, un direccionamiento a partir de la figura del trabajo social, como acción solidaria que puede ser ejercida por personeros expertos, en aras de la defensa de los derechos humanitarios de tercera generación.

Vale decir, la paz, el desarrollo de los pueblos y de las personas y un ambiente sano, los contextos en los cuales se desarrollan las crisis humanitarias, muchas veces son productos de los conflictos armados, ya sea interno o externo o en aquellos eventos de fuerza mayor cuando ocurren desastres naturales, lo cual repercute de manera directa en la población de un país, como una de las consecuencias del conflicto armado, adicional al desplazamiento forzado y la aparición de personas refugiadas.

Es así cuando se dan estos fenómenos que la población en general esta vulnerable, además de que el Estado entra en una fase en la cual se le dificulta cobijar y suplir las necesidades básicas, por tal razón no pueden gozar plenamente de sus DDHH y en especial de aquellos que son inherentes a su subsistencia, de manera individual como colectiva, como por ejemplo: el derecho a la vida, a un ambiente sano y a la paz entre otros. Tal como lo afirma Relinque (2015):

Estas personas y comunidades tienen el derecho a vivir con dignidad, por lo que necesitan ser ayudadas, bajo el ápice de la solidaridad, por organismos humanitarios, ya que sus estados fallan en la función de protección, para la vuelta a la normalidad, para que se frene su situación de vulnerabilidad y sea posible su posterior desarrollo (p. 3).

En plena consonancia con el criterio anterior, y exponiendo los diferentes derechos humanos de tercera generación, aludiendo en tal sentido los siguientes: derecho a la paz, al desarrollo económico, a la autodeterminación, a un ambiente sano, a beneficiarse del patrimonio común de la humanidad y a la solidaridad, como principio 
fundamental que ha de regir entre los pueblos, cuando se trata de crisis poblacionales que amenazan el porvenir de sus ciudadanos.

Sobre esta misma situación, considera Sáchica (2010) a esta nueva generación de derechos humanos, caracterizada no sólo por su generalidad, la cual supera la cortedad del individualismo, no sólo por su realismo, que sobrepasa la estrechez de la concepción socialista, como un regreso de todas las discriminaciones injustificadas, a la raíz profunda de lo humano, a la preocupación por la salvación de la especie, de manera integral, holística, alejada a la vez de los particularismos nacionalistas como el racismo, el clasismo y el ideologismo divisor y con perjuicio a los hombres.

De lo afirmado por el tratadista Sáchica (2010), la concepción sobre los DDHH y el DIH hoy en día se cataloga como el nacimiento de un humanismo actualizado a las necesidades de las épocas contemporáneas, un humanismo no de carácter individual, clasista o racionalista, si no que propende por dar respuestas y soluciones prácticas frente a los riesgos de la guerra y la supervivencia del hombre en sí.

Observando la situación real de algunos países de Latinoamérica, como es el caso más actual de Venezuela, la exigencia del reconocimiento de los derechos humanos se hace compleja, en razón a que un Estado dictatorial niega el pleno goce de estos derechos, por tal el disfrute de los mismos no son efectivos de forma individual o colectiva (Sáchica, 2010). Es así como para un buen disfrute de los derechos humanos, ha de establecer una comunidad política bien pensada, como la que a la luz de la simple razón natural y el sentido común concibió Moro en Utopía, pensada comunitariamente, a pesar de la reiteración, porque lo primero es asegurar la existencia del grupo total y, desde allí, luego, con el correr del tiempo y como su coronamiento, llegar a la satisfacción de lo que corresponde al interés de sus partes.

Uno de los derechos más exclamado por las personas a nivel mundial después de la dignidad humana es la anhelada paz, derecho que actualmente dada la vulneración de derechos, intereses económicos proveniente de la guerra, la desigualdad social entre otros factores ha hecho que se precarice este derecho, se resalta que así como 
la propiedad privada en la época del individualismo era uno de los derechos más exclamado por las personas, hoy en día a los nuevos movimientos sociales y de la concepción del nuevo humanismo de los derechos humanos ha tenido el derecho a la paz una preponderancia frente a otros derechos de carácter individual o colectivos. Los Estados hoy en día reconocen que si bien han dado pasos grandes para el cumplimiento de las normas del DDHH y del DIH con la ayuda de organismos internacionales, todavía falta mucho por hacer por parte de estos, en razón a diferentes factores como por ejemplo los conflictos de carácter armados ya sea guerra interna o externa, el terrorismo, las amenazas entre Estados y la guerra armamentista entre los mismos, diferentes conflictos políticos, religiosos, etc.

Pero, sobre ese trágico escenario, se perfila un apoyo internacional solapado a las corrientes subversivas que desestabilizan gobiernos y anarquizan sociedades. Se enraíza en algunas sociedades latinoamericanas un impúdico mercado de armas, como una especie de renacimiento de viles prácticas mercenarias, a la par de incesantes persecuciones políticas, conllevando el exilio masivo, no solo de los propios perseguidos, sino de todo aquel que sienta amenazada su seguridad y su tranquilidad social. No habiendo, en tal sentido, lugar a la paz, como figura insoslayable del buen vivir de los individuos en la sociedad en la cual se desenvuelve.

Esa realidad ha sido evidenciada en el siglo XX y lo que transcurre del siglo XXI, dado a las polarizaciones políticas de izquierdas y derechas que decaen en un absurdo bipolarismo donde la población sin argumentos válidos se enfrentan por tal. Mientras que la sociedad en general no exista el respeto hacia el pluralismo ideológico de gobiernos, partidos políticos, ciudadanos, y no se respete por las grandes potencias la libre determinación de los pueblos por parte de los países denominados países pequeños en su situación económica, es así cuando se realice una justa retribución de la riqueza y entre los países considerados grandes potencias frente a los países necesitados se podría afirmar que podría darse el derecho a la paz bajo los principio de equidad y justicia. Mientras lo anterior no se realice este derecho tiende a su afectación. 
De allí que pueda inferirse en este estudio que si bien las teorías relacionadas con esos temas, entienden los derechos colectivos como de tercera generación, y estos derechos surgen frente a necesidades sociales colectivas, su reconocimiento solamente se inicia a través de instrumentos internacionales diversos y a partir de su inclusión en legislaciones patrias, entre las cuales, si bien resaltan normas constitucionales y legales, por ejemplo, en el caso de Colombia, en la búsqueda de la verdad, la justicia, la paz, el restablecimiento de los derechos y la tranquilidad de los pueblos (Meléndez, Paternina y Velásquez, 2018). No menos cierto es que, grupos adversos a la armonía social, desvían los acuerdos y alianzas que bien pudieran lograrse desde de tantos años de conflictos.

Debe entenderse en este apartado la clara necesidad de las comunidades de intervenir sus espacios en aras de la creación de sus derechos al ambiente sano, el derecho al desarrollo, a la autodeterminación de los pueblos, el derecho a la paz, los derechos de bienestar de usuarios y consumidores, el espacio público armónico, en equilibrio, la salubridad pública, el derecho al patrimonio cultural, el derecho a la moralidad administrativa, entre otros aspectos, que tocan una sana realidad del hombre.

Sobre esta base, se erige en la actualidad entonces esa característica central de los derechos colectivos, y que comporta su fundamento ético: la solidaridad, como forma de adhesión de los pueblos, en apoyo a su devastación, a su deterioro derivado de los conflictos en los cuales se ha visto inmerso, o unida a la urgencia de desarrollar acciones preventivas para evitar el deterioro de los mismos.

Esa solidaridad se presenta, en tal sentido, como necesidad imperativa para afrontar debidamente los resultados equivocados de las acciones humanas expresados como crisis ambiental y civilizatorias. A la par, se suma su naturaleza participativa, como mecanismo igualmente diferenciador de los derechos colectivos, en virtud de lo cual se reconoce una doble titularidad frente a estos derechos, generando la posibilidad de defensa de lo colectivo como si formara parte del patrimonio personal. 
Incluso, en el caso del derecho ambiental, específicamente, tales exigencias y tales derechos se corresponden con la necesidad de acceder, usar, producir, conservar, proteger e intercambiar adecuadamente los bienes naturales y ambientales en beneficio de todos los humanos actuales y futuros. Pero se trata de una tarea ejercitada bajo un denominador común: la solidaridad, el carácter colectivo de las medidas ejecutadas.

Es así que, tales derechos surgen en un periodo histórico reciente como respuesta a los graves problemas generados por la crisis ambiental y civilizatoria, manifiesta en diversas acciones cada vez más grandes, graves y globales. Contaminaciones de los elementos y bienes ambientales, así como la sobreexplotación, erosión y perdida de los recursos y bienes naturales y ambientales, lo cual va en desmedro de la calidad de vida de los habitantes de un país en crisis.

Vigencia de los derechos humanitarios desde la perspectiva de la solidaridad en la actualidad en Latinoamérica... casos puntuales de vigor jurídico

En este punto resulta fácil aludir a la vigencia de los derechos debatidos. Hoy más que nunca el principio de solidaridad se instituye como la necesidad del apalancamiento entre los pueblos, de manera que se produzca la unión de los mismos, su protección, la defensa de intereses particulares, pero que, dada la migración producida en los últimos años en el mundo, en virtud de la globalización y la mundialización, de la necesidad de progreso y de apoyo político, económico y cultural, que sobrepasa los límites de la unidad e interesa a todos.

No obstante esa vigencia indiscutible de los derechos humanitarios, enfatiza ciertas situaciones clave en el deterioro de la ayuda y la incorporación de valores humanos en el orbe. A saber, el poder irresistible de las empresas transnacionales, la rigidez del crédito internacional, la imposición de precios inaceptables para las materias primas procedentes de países del Tercer Mundo, la política discriminatoria en las inversiones del capital foráneo, la irresistible competencia desleal, la sustracción de toda consideración humana 
en el tratamiento de las cuestiones financieras que terminan siendo proyección de los conflictos políticos mundiales (Sáchica, 2010).

Siendo concomitante con la visión anterior, se puede afirmar que frente a la explotación económica ya sea de países o de multinacionales motivado por lo denominado capitalismo salvaje, no se debe por ninguna circunstancia aceptar la dominación de los derechos naturales de las personas ni de aquellos derechos considerados como patrimonio de la humanidad. Su explotación, deterioro y destrucción debe ser rechazados, ya que estos derechos patrimoniales deben ser compartidos en forma general con todas las personas, ya sean estos nacionales o no del país y que le pertenezca ese bien común y natural a la humanidad.

Por otro lado, señala el mencionado autor (Sáchica, 2010) cuando se realiza actos de ocupación hacia un país, esto no da derecho de ejercer dominio y utilización de los bienes con vocación de patrimonio de la humanidad de forma exclusiva del país que se está ocupando, ya que de ese patrimonio son titulares todas las personas y por tal razón no deben ser utilizados sin ninguna restricción,y de no ser así, afirma el derecho al desarrollo como un componente para lograr el derecho a la paz, cuando las grandes potencias se aprovechan de forma exclusiva acaparando estos. Esos derechos se tornan difíciles de acceder o disfrutar y el derecho al desarrollo y a la paz resulta más complejo para llegar a estos, muy a pesar que son derechos interdependientes, como lo son todos los intereses comunitarios.

En este apartado, queda para la reflexión y el análisis el pensar de Bustamante (2010), cuando afirma el progreso de los derechos de tercera generación, pero también que el desarrollo de una cuarta generación de derechos humanos pasa por una apropiación social de las nuevas tecnologías. En este sentido, una mayor conciencia de la importancia de la promoción de un conocimiento libre y participativo dentro de una cultura digital se revela así, como una de las metas intermedias que debe plantearse hoy en día si realmente se pretende lograr una sociedad más humana, justa y solidaria, en la que ciencia y tecnología sean herramientas fundamentales en la promoción de fines socialmente relevantes. 
Lo planteado no resulta aún tangible, si se parte del criterio de Camen (2015), quien alude en la actualidad a los conflictos del futuro. En este sentido, muy específicamente menciona que hoy se requiere evaluar la legalidad de las nuevas armas porque esto contribuye a garantizar para las partes en un conflicto ser capaces de conducir las hostilidades de conformidad con sus obligaciones internacionales. Desafortunadamente, muy pocos Estados han puesto en marcha un proceso formal para llevar a cabo una revisión legal de nuevas armas propuestas. El hecho de que un número creciente de Estados estén desarrollando capacidades de guerra cibernética, defensivas u ofensivas, refuerza la urgencia de estas preocupaciones.

Explica que la guerra cibernética es el uso de un código de computadora -unos y ceros- para causar la muerte, lesiones, destrucción o daños durante los conflictos armados. Hasta ahora, el uso reportado de acciones de guerra cibernética no ha conducido a consecuencias humanitarias dramáticas. Parece que son posibles ciberataques contra sistemas de transporte, redes eléctricas, presas y plantas químicas o nucleares. Este tipo de ataques podrían tener consecuencias de amplio alcance, resultando en bajas civiles significativas y daños a bienes de carácter civil; cuestiones estas que, en general, no han sido reguladas por las Comisiones de Derecho Internacional Humanitario (DIH).

En este punto, resulta clara la necesidad de la adhesión a este estudio del Informe anual de actividad 2018, el cual es un registro de las actividades que el Comité Internacional de la Cruz Roja (CICR, 2018) ha llevado a cabo sobre el terreno en todo el mundo a lo largo del año. Estas actividades contribuyen al cumplimiento del cometido de la institución de proteger la vida y la dignidad de las víctimas de la guerra, así como de promover el respeto del Derecho Internacional Humanitario.

En el informe se desarrollan las acciones ejecutadas a favor de los destinatarios de las normas humanitarias, y a la vez se realiza un llamado a la solidaridad de los pueblos en la atención a las víctimas de la guerra y de otros abusos y atropellos que atentan contra los derechos humanos fundamentales. Es así que se concluye, sobre el 
tema, que se ha de habilitar la participación e intervención de diversos actores para la canalización de las acciones a ejecutar.

Destaca en el informe que ni un solo sector puede responder por sí mismo, a la amplia y profunda crisis humanitaria: el progreso va a requerir un soporte fuerte de los Estados, organizaciones internacionales y la sociedad civil en su amplitud. Mientras, lo neutral, imparcial y espacios humanitarios independientes son la mejor manera para reiniciar las vidas y reconciliar, los practicantes humanitarios pueden generar esfuerzo en las líneas fronterizas y guiar a otros por el camino de las sociedades desfragmentadas, en los desafíos de seguridad y necesidades multifacéticas. En los años por venir, se continuará trabajando con los socios, confiando en sus habilidades, experticia, y contribuciones financieras para hacer un impacto.

Cabe destacar también en este apartado, como caso puntual de Latinoamérica, lo relativo a los retos de los jueces de Colombia en los próximos años y su análisis de la necesidad de integrar el DIH. Sobre el particular, Rojas (2017) expone lo siguiente:

[...] el principal reto que tienen los jueces colombianos en relación con la aplicación del DIH es de aproximarse a él más decisivamente conociendo y sabiendo que es una ley especial. Eso permitirá que en la solución de casos que tengan que ver con conflictos armados, tanto en materia penal como en materia de reparación de daños, se le dé una aplicación preferencial.

Con toda seguridad, por supuesto, el Tribunal para la Paz tendrá que hacer lo propio, pero el reto es que sea una aplicación mucho más generalizada y no una aplicación solo de expertos, como hasta ahora parece que se viene haciendo. Por ejemplo, las Altas Cortes suelen estar haciendo aplicaciones de distinta índole del Derecho Internacional Humanitario, pero los jueces en general no lo hacen.

El llamado es a utilizarlo, primero porque es una norma de rango constitucional, pero también es una ley especial y se cree que en todos los asuntos en donde esté de por medio conflictos judiciales relacionados con el conflicto armado, debe ir el DIH. En similar sentido a lo expresado destaca Olásolo (2017) con lo que sigue: 
La primera cuestión que tenemos en cuanto a aplicación del DIH es que continuamos con el proceso de modificación de los protocolos por parte de la fuerza nacional para que se ajusten en su contenido a lo que es realmente la aplicación del derecho internacional humanitario y en particular, del protocolo adicional II y del artículo 3 común... Creo que el primer reto fundamental es retomar, terminar con esa dinámica de salvaguarda del personal y tratar de ajustar los protocolos a través de los cuales actuamos a lo que dice realmente el derecho internacional humanitario y en particular, como lo interpreta el Comité Internacional de la Cruz Roja.

En segundo lugar, eso va a tener una repercusión muy importante, ... deslindar si nos encontramos en una situación en la que se aplica o no se aplica el DIH.

También determinar en qué ocasiones podemos realizar operaciones de acuerdo al DIH y cuando no podemos llevar a cabo este tipo de operaciones... ver si estamos en un conflicto armado o si estamos efectivamente ante una situación que amerite otro tipo de operativo. Finalmente, ... junto al DIH, a pesar de que estemos en un conflicto armado, siempre tenemos que aplicar el Derecho Internacional de los Derechos Humanos y el Derecho Internacional Penal. Es un paquete conjunto que se interpreta de manera coherente y sistémica y que no puede significar que aplicamos uno en detrimento del otro.

De acuerdo a lo planteado por los magistrados expertos en el área estudiada, se evidencia, entonces, que se requiere en la práctica judicial, atender a las normativas específicas del DIH, por un lado, sin desatender lo que al efecto del mismo conflicto contemplen otras legislaciones imperantes en cada país en particular. Y, asimismo, deberá estudiarse cada caso en específico, buscando la justicia normativa.

Ello implica el conocimiento exigible en los jueces de Colombia con relación a los temas que debe resolver. Por un lado, destaca la normativa aplicable, de acuerdo a las normas internacionales, propias del DIH, sin obviar aquellas devenidas de la legislación internacional de los derechos humanos, que en definitiva no se pueden disociar en la implementación jurídica de las disposiciones que aplican en cada caso concreto. 
Cabe destacar también en este inciso, como en la actualidad, en una situación atípica, en razón del problema fronterizo de huida del país en franco rechazo a la ideología política del gobierno de Venezuela, por parte de la mayoría de los ciudadanos venezolanos, se ha producido un nivel altísimo de diáspora de los mismos, hacia las tierras más cercanas (Colombia, Perú, Chile, entre otros países involucrados). Desencadenado el virus de la xenofobia, impidiendo el derecho de migrar que tienen todos los individuos en el mundo, pero ante lo cual muchos ciudadanos de esos países, los defienden, con indignación y solidaridad, ante las agresiones provocadas.

Ante ello, el Comité Internacional de la Cruz Roja en Perú, junto a algunas fundaciones que tienen la iniciativa de presentar proyectos de defensa de las víctimas de xenofobia, unen fuerzas para mostrar que desde la solidaridad es posible ser mejores personas (CICR, 2019). Se hace un llamado al respeto, la humanidad, y permitir la perseverancia. Eso es lo único que piden los migrantes para poder llevar a cabo su trabajo y tener una oportunidad de salir adelante.

Estas personas migrantes pasan por el temor, la ansiedad y las vulnerabilidades de emprender su camino hacia un futuro mejor "todos somos migrantes contra la xenofobia" (CICR, 2019). En la ruta, pueden encontrarse en riesgo y necesitar protección o asistencia. De allí que el CICR y las fundaciones y asociaciones sin fines de lucro se unen para sensibilizar sobre la importancia de la convivencia y el rechazo a la xenofobia. Ello porque son países con raíces comunes, con descendencia de algún familiar migrante, por lo cual se llama a dar la mano de manera solidaria.

Reflexiones sobre la vocería de los derechos humanitarios solidarios...

una necesidad impostergable en países latinoamericanos

Resulta obvio, en la actualidad, la variedad de tragedias humanitarias que devastan el mundo. Entre ellas, los conflictos armados (internos o internacionales) que parecen alzarse como una de las principales causas de tragedias humanitarias. Así lo destaca Rosales (2014), afirmando que el ascenso del número de muertos civiles 
refleja una situación lamentable. Además, todo conflicto armado ha venido generando una afectación múltiple de derechos, independientemente de quienes sean los que se enfrentan en las hostilidades y cuáles sean sus razones.

En estudio reciente, Rosales (2014) establece que frente a la violencia que surge por la oposición de dos grupos armados, existe un imperativo jurídico para las partes de proteger a la población civil que sufre el impacto, directo o indirecto, del enfrentamiento. Desde el Derecho internacional humanitario (DIH) se erige, por tanto, una obligación jurídica de ayuda o asistencia humanitaria a quienes conforman la población civil.

Ahora bien, pese a ser los conflictos armados un escenario recurrente, no son la única razón que acarrea una calamidad con implicancias humanitarias: los desastres naturales $\mathrm{u}$ otras acciones del hombre pueden tener un impacto similar o mayor en el daño. En este escenario, Rosales (2014) se pregunta si es posible sostener que el DIH constituye fundamento jurídico suficiente para sustentar una asistencia humanitaria fuera de un contexto de conflicto armado, lo cual debe negarse ya que precisamente se erigió y convirtió prácticamente en un derecho especial para este tipo de situaciones de la humanidad, en sus diferentes entornos.

De allí que, de manera franca, algunos expertos, otros pensadores de la paz, han hecho eco de la necesidad social de los derechos humanos solidarios, pudiendo establecer, no fórmulas mágicas, pero si mecanismos concretos, quizá fatuos, por impertinentes, para algunos, pero que pudiesen orientar acciones para el regreso a la paz de los pueblos, a la recuperación de su conciencia y la tranquilidad de las comunidades, como sentido y significado de los estados, de las naciones, de los gobiernos, y en fin, al goce del beneficio del bienestar, como elementos culmen en la historia del hombre en el mundo.

En ese sentido, Sáchica (2010) propone abiertamente la eliminación de la industria bélica, la supresión de las tortuosas intervenciones en los asuntos domésticos de países en crisis, la reducción, siquiera, de los gastos militares, la lucha general contra el terrorismo, no importa cuál sea su motivación, la condena de toda violación, la moderación 
de la exaltación nacionalista, en suma: el respeto, la tolerancia, el diálogo, la concertación para el reencuentro y el reconocimiento del otro como igual, como no adversario ni competidor ni, menos, enemigo, la veneración de la vida, como algo sagrado son el largo camino de la educación para la paz.

A la par, bien lo propone Relinque (2015) cuando refiere la indiscutible necesidad de la intervención en el ámbito de la acción humanitaria, disciplina que media en tales circunstancias de emergencia para asistir, proteger y socorrer a estas personas, pudiendo ayudar a los sujetos y comunidades víctimas de desastres a su recuperación y rehabilitación. Y, además, empoderar a los sujetos de derechos (las propias personas y comunidades) y a los sujetos de obligaciones (autoridades y organismos) para que el derecho a la paz, al desarrollo y a un medio ambiente sano, sea ejercido y respetado por y para todas las personas de estas comunidades afectadas.

Todo ello puede ser alcanzado dándole una mirada de manera íntegra, como lo señala Relinque (2015) desde un enfoque integral y multidisciplinar que atienda todas las dimensiones de la vida desde diferentes perspectivas. Para ello se identifican tres posibles líneas de intervención: asistencial, la cual busca la recuperación psicosocial y cultural más inmediata, mediante la atención y acompañamiento para la reconstrucción de tejido social y la información de recursos necesarios y datos básicos; intervención promocional, que busca el empoderamiento de las personas para que sean agentes de sus propias vidas y transformen su situación posibilitando su desarrollo; y preventiva, persiguiendo la construcción de una cultura de paz promoviendo el diálogo pacífico.

Sobre el mismo particular, plantea Ortega (2016) que, en un mundo de inmediatez, no existe explicación para no tener documentado en tiempo real las violaciones a derechos humanos y más aún, no proponer nuevas formas de acceso a la justicia. Se hace impostergable un llamado a la acción para repensar la responsabilidad sobre tales y graves violaciones. Esta es una propuesta innovadora y transformadora para conectar a víctimas de abuso, empoderarlas y generar una comunidad que brinde información en tiempo real sobre el trabajo 
de cada dependencia de gobierno que debería proteger y garantizar estos Derechos.

En tal sentido, se debe denunciar el abuso y la violencia en contra de infantes y adultos. Realizar diagnósticos acerca de los patrones de violencia, por un lado, de perjuicios por el otro, pudiendo, desde allí, sobresalir líderes comunitarios que ayuden al empoderamiento de estas víctimas y sus familiares, logrando una mejor calidad de sus defensas, y, por ende, a una mejor justicia. A la par, se debe estar al pendiente de aquellos funcionarios públicos que, a sabiendas de las crueldades, atropellos en contra de seres humanos, no aperturen expedientes para castigar los culpables de faltas y delitos, por el contrario, también se debe hacer reconocimiento de las buenas prácticas y conductas, buscando motivar un mayor y mejor desempeño. Esto se convierte en una apuesta que propone mirar más ampliamente la promoción de los Derechos Humanos como garantía de un Estado menos violentado también al interior.

Reitera Maurer (2019), en su carácter de presidente del Comité Internacional de la Cruz Roja, que hoy, más que nunca, ante los diversos conflictos armados que acontecen en el mundo, es imperante resaltar la vigencia del Derecho Internacional Humanitario (DIH), las 'leyes de la guerra'. Aseveró que han pasado 7 décadas desde que las naciones del mundo, con la presencia del CICR como experto, firmaron dichas convenciones. Estas convenciones, junto con sus Protocolos adicionales, son la piedra angular del DIH, es decir, el conjunto de normas jurídicas que regulan las formas en que se pueden librar los conflictos armados y que intentan limitar los efectos de éstos en los civiles y en todos aquellos que no participan en las hostilidades. Estos mismos Protocolos se dividen en cuatro:

- El I Convenio, que protege a los heridos y a los enfermos de las fuerzas armadas en campaña terrestre.

- El II Convenio, que protege a los heridos, los enfermos y los náufragos de las fuerzas armadas en el mar.

- El III Convenio, que establece las normas de protección para los prisioneros de guerra.

- El IV Convenio, que protege a las personas civiles. 
Asimismo, señala como los Convenios de Ginebra, incluso durante conflictos armados, tanto internacionales y no internacionales, recuerda a las personas que combaten como deben actuar bajo ciertos límites en cuanto a las acciones que pueden tomar y que siempre se debe respetar la dignidad humana. Además, son de los pocos tratados internacionales ratificados a nivel global. Su carácter universal refleja los valores éticos humanitarios que contienen y refuerzan la vigencia de sus disposiciones para el mundo contemporáneo.

Por su parte, Durham (2016), desde la Dirección de la Unidad de Derecho Internacional y Doctrina del CICR, enfatiza la necesidad de no desestimar el derecho de la guerra, alegando que nunca antes ha sido tan conocido entre el público; nunca antes ha sido tan intensa la indignación que se expresa cuando se violan sus principios. Se debe asegurar el fortalecimiento del respeto de las leyes de la guerra, siendo algo que el mundo necesita con urgencia. En este sentido, los hospitales bombardeados, o las poblaciones sitiadas o millones de personas arrancadas de sus hogares, incitan a preguntar si las leyes que rigen los conflictos armados realmente sirven para algo, o se han convertido a la fecha en letra muerta.

\section{Conclusiones}

En la historia de los pueblos, la búsqueda incesante por parte del hombre, de sus propios derechos y garantías, ha sido una constante. De allí el logro de legislaciones patrias que amparan, tutelan, la vida, la verdad, la paz, y en este sentido, desarticulan una serie de normas adjetivas en beneficio de los individuos, y en desmedro, de condiciones adversas a su calidad humana.

No obstante, se ha dado en diversas oportunidades, situaciones conflictivas que perjudican esa clara determinación de la justicia de los pueblos, lo que ha conllevado la situación negativa de la guerra, la tensa calma que hace imperar el ánimo agresivo, en fin, la ausencia de la fraternidad, de la solidaridad de los pueblos, la ayuda incesante, la protección entre sí, el sortear el conflicto por las vías de la razón, del derecho, de la conciliación de intereses sobre la base de lo común humano. 
Más aún, los mecanismos de control supraestatal no son operantes todavía. Subsiste el dominio de la fuerza en razón de lo cual, la alineación de países, la integración de bloques no ha descubierto las aristas de la paz, por el contrario, es fuente de nuevos enfrentamientos a mayor escala. En estas condiciones, el hombre se ha vuelto cada vez más agresivo, en detrimento del llamado a la paz que debe devenir de su propia conciencia, cuando su creación ha sido bien fundamentada.

De allí que sea impostergable un repensar de los derechos humanos, por parte de los individuos, por parte de los estados y de los organismos internacionales que han sido creados con tales fines. Se debe buscar que impere el efecto disuasivo de la guerra, eliminar la creencia en la agresividad natural del individuo, los esquemas políticos disonantes de enemistar por parte de politiqueros, integrantes de partidos políticos.

Debe encausarse la vida de los pueblos negociando el desarme, mantener el diálogo en los debates, como estrategia válida para la búsqueda de la paz y el goce de los derechos humanitarios, en franca atención a la prospectiva, al futuro inmediato de los derechos humanos, que hasta ahora han sido socavados, no mostrándose como piedra angular en la adhesión de los pueblos.

En este sentido, la solidaridad se muestra como necesaria a las sociedades modernas, en aras de su propia armonía social, y en desmedro de pretendidos antivalores de pseudo-políticos que perfilan sus vidas, sus acciones y su historia, en franca ansia de poder, y de deterioro de los pueblos que inútilmente gerencia. Para ello, hace falta un nuevo llamado a los controles jurídicos y las precauciones belicistas.

Es así que, mucho se ha discurrido en Colombia sobre los derechos humanos, sobre el goce de los derechos humanitarios, sobre la solidaridad de los pueblos vecinos y hermanos, pero las prácticas desleales, la ausencia de credibilidad en los patrones mostrados, y la falta de valores humanos en los personajes imbricados, han inducido tácticas erróneas, que no permiten el logro de la paz verdadera de sus habitantes. No obstante, persiste el ánimo sobre tratados de justicia y 
verdad, que en definitiva asegure la satisfacción de las necesidades vitales, las condiciones de dignidad de los ciudadanos, sumado a un óptimo desarrollo económico y social, un crecimiento suficiente en la disponibilidad de bienes y servicios distribuidos con equidad, con sentido de desarrollo comunitario, no dependiente, autogenerado, auto sostenido.

Ello supone la idea de la convivencia sana entre las naciones, un equilibrio armónico entre los actores involucrados, el compromiso de las partes interesadas, la sinceridad de las culturas, y el deseo de imponer la justa solidaridad entre los países imbricados, trayendo consigo un reajuste, un nuevo orden económico mundial, un equilibrio de intereses que elimine todo conflicto de intereses, y encamine acciones hacia el progreso local y mundial.

\section{REFERENCIAS}

Bustamante, J. (2010). La cuarta generación de derechos humanos en las redes digitales. Revista Telos, 85, 1-13. Recuperado de https://telos.fundaciontelefonica.com/archivo/numero085/la-cuarta-generacion-de-derechos-humanos-en-lasredes-digitales/?output $=$ pdf

Camen, A. (2015). El respeto al DIH no solo ha de hacerse cuando hay conflicto. [Online]. Disponible en https://www.icrc.org/ es/document/colombia-tres-expertos-discuten-los-desafiosactuales-del-dih

CICR. (2019, 15 febrero). Todos somos migrantes contra la xenofobia. [Online]. Recuperado de https://www.icrc.org/es/document/todos-somos-migrantes-teatro-contra-la-xenofobia

CICR. (2018). Informe anual de actividad 2018. [Online]. Disponible en https://www.icrc.org/data/files/annual-report-2018/icrcannual-report-2018.pdf

CICR. (mayo 11, 2007). Los Protocolos adicionales I y II a los Convenios de Ginebra de 1949 - Ficha técnica. [Online]. Recuperado de https://www.icrc.org/es/doc/resources/documents/ legal-fact-sheet/protocols-1977-factsheet-080607.htm 
Cruz Roja Española. (2018). Definición del Derecho Internacional Humanitario. [Online]. Disponible en http://www.cruzroja. es/portal/page?_pageid=878,12647036\&_dad=portal30\&_ schema $=$ PORTAL30

DDI. (2019). Derecho Internacional Humanitario (DIH). [Online]. Disponible en http://www.oas.org/es/sla/ddi/derecho_internacional_human itario.asp

Durham, H. (Abril 7, 2016). Atrocidades en los conflictos: los Convenios de Ginebra, más necesarios que nunca. [Online]. Disponible en https://www.icrc.org/es/document/atrocidades-en-los-conflictos-los-convenios-de-ginebra-mas-necesarios-que-nunca

Gasser, H. P. (2010). Algunas reflexiones acerca del futuro del Derecho Internacional Humanitario. Revista Internacional de la Cruz Roja, 9(61), 18-26. https://doi.org/10.1017/ S0250569X00003320

Maurer, P. (Abril 8, 2019). Peter Maurer en Perú: 70 años de la Convención de Ginebra. Presidencia del Comité Internacional de la Cruz Roja (CICR). [Online]. Disponible en https://www.icrc.org/es/document/peter-maurer-en-peru70-anos-de-los-convenios-de-ginebra

Meléndez, Y., Paternina, J. y Velásquez, D. (2018). Procesos de paz en Colombia: derechos humanos y familias víctimas del conflicto armado. Jurídicas CUC, 14(1), 55-74. https://doi. org/10.17981/juridcuc.14.1.2018.03

Narváez, B., Matzumoto, N., Mira-Olano, L. y Zúñiga-Bolívar, A. (2019). Los derechos e inclusión de las víctimas del conflicto armado vs. las obligaciones Estado colombiano. Jurídicas CUC, 15(1), 321-352. https://doi.org/10.17981/juridcuc.15.1.2019.13

O'Donnell, G. (2004). La democracia en América Latina. Hacia una democracia de ciudadanas y ciudadanos. El debate conceptual sobre la democracia, Buenos Aires: PNUD. 
Olásolo, H. (mayo 25, 2017). Los retos de los jueces en Colombia: la academia opina. [Audio]. Disponible en https://www.icrc. org/es/document/los-retos-de-los-jueces-en-colombia-la-academia-opina

ONU. (2018). Tratado sobre el Comercio de Armas. [a/res/73/36]. Recuperado de https://undocs.org/pdf?symbol=es/A/RES/73/36

ONU.(1968). Derechos humanos en los conflictos armados. [a/res/2444]. Recuperado de https://undocs.org/es/A/RES/2444(XXIII)

Ortega, S. (2016). Haciéndonos Cargo: La apuesta por transformar los derechos humanos desde Argentina y para América Latina. [Online]. Disponible en https://www.changemakers. com/es/derechoshumanos/blog/haci\%C3\%A9ndonos-cargola-apuesta-por-transformar-los-dh.pdf

Perren-Klinger, G. [@CICR_co]. (2015, Septiembre 10). Es fácil firmar y ratificar las normas humanitarias y el \#DIH. Cumplir es lo difícil". [Tweet]. Disponible en https://twitter.com/ cicr_co/status/642073962760011776

Relinque, A. (2015). Derechos humanos de tercera generación y procesos de cooperación internacional desde el trabajo social. [Trabajo de grado]. Universidad de Cádiz, España. Disponible en http://hdl.handle.net/10498/18231

República de Colombia. Asamblea Nacional Constituyente. (1991). Art. 93. [Constitución política]. Gaceta Constitucional, $1(114)$.

Rojas, D. (2017). Los retos de los jueces en Colombia: la academia opina. [Online]. Disponible en https://www.icrc.org/es/document/los-retos-de-los-jueces-en-colombia-la-academia-opina Rosales, P. (2014). La importancia de la asistencia humanitaria en la actualidad. Instituto de Democracia y Derechos Humanos de la Pontificia Universidad Católica del Perú. [Online]. Disponible en http://idehpucp.pucp.edu.pe/opinion/la-importancia-de-la-asistencia-humanitaria-en-la-actualidad/

Sáchica, L. C. (2010). Constitucionalismo mestizo. México, D.F.: UNAM. 
Sánchez, M. H. (2007). Estado, derecho internacional humanitario y mision médica. compromiso de la universidad frente al problema humanitario. Principia Iuris, 7(7).

Serrano, S. y Vázquez, D. (2016). Los derechos humanos en acción: operacionalización de los estándares internacionales de los derechos humanos. México, D.F.: FLACSO. Disponible en http://www.cjslp.gob.mx/seminario/programa/Panel\%20IV/Enfoque\%20 de\%20 derechos.\%20Operacionalizacio\%C2\%B4n\%20de\%20 esta\%C2\%B4ndares\%20internacionales.pdf

Uribe, D. (1983). Derecho constitucional de la libertad. La tercera generación de derechos y la paz. Bogotá, D.C.: Temis, Plaza \& Janes.

Jaime Bermejo Galán es Doctor en Ciencias Políticas de la Universidad Urbe de Maracaibo (Venezuela). Abogado con Magíster en Derecho Administrativo y Especialista en Derecho Constitucional de la Universida Libre (Colombia). Docente de la Universidad Simón Bolívar (Barranquilla, Colombia). https://orcid.org/0000-0003-09172506

Juan José Lamadrid es Abogado con Magíster en Derecho de la Universidad Libre. Docente de la Universidad Libre. (Barranquilla, Colombia). https://orcid.org/0000-0003-4927-4590 